\title{
The effect of patient positioning on ultrasound landmarking for cricothyrotomy
}

\author{
Lauren Arthurs, MD · Shannon Erdelyi, MSc $\cdot$ Daniel J. Kim, MD (1)
}

Received: 20 January 2020/Revised: 28 June 2020/Accepted: 12 July 2020/Published online: 7 October 2020

(C) Canadian Anesthesiologists' Society 2020

\begin{abstract}
Purpose Our primary objective was to assess the difference in position of the ultrasound-guided landmark of the cricothyroid membrane (CTM) when performed with the supine patient positioned at different head of bed (HOB) elevations.

Methods In this prospective observational study of patients presenting to the emergency department with non-life-threatening complaints, subjects underwent ultrasound-guided landmarking of the CTM with HOB elevation at $0^{\circ}, 30^{\circ}$, and $90^{\circ}$. A linear mixed effects regression model was used to assess the change in the CTM landmark associated with head position. We used a second adjusted linear mixed effects model to assess possible confounding patient factors associated with these changes. Results One-hundred and ten patients were enrolled, with a median [interquartile range] age of 39 [29-59] yr and 51:49 female:male ratio. Head of bed elevation at $30^{\circ}$ and $90^{\circ}$ resulted in a cephalad change in the CTM landmark of $2.7 \mathrm{~mm}(99 \%$ confidence interval [CI], 1.7 to 3.8 ; $P<0.001)$ and $4.2 \mathrm{~mm}(99 \% \mathrm{CI}, 3.2$ to $5.3 ; P<0.001)$ respectively compared with the landmark at $0^{\circ}$. Body mass index (BMI) was associated with a change of $4.6 \mathrm{~mm}(99 \%$ CI, 0.5 to 8.7; $P=0.004)$ for $B M I \geq 30$ compared with
\end{abstract}

Prior presentations: American Institute of Ultrasound in Medicine Annual Convention, New York, NY, 26 March 2018; Canadian Association of Emergency Physicians (CAEP) Annual Conference, Calgary, Alberta, 28 May 2018.

\section{Arthurs, MD - S. Erdelyi, MSc}

Department of Emergency Medicine, University of British Columbia, 2775 Laurel St, Vancouver, BC V5Z 1M9, Canada

D. J. Kim, MD ( $\square)$

Department of Emergency Medicine, University of British Columbia, 2775 Laurel St, Vancouver, BC V5Z 1M9, Canada e-mail: dkim000@gmail.com

Department of Emergency Medicine, Vancouver General Hospital, Vancouver, BC, Canada
$<18.5 \mathrm{~kg} \cdot \mathrm{m}^{-2}$ The impact of patient age on distance depended on $\mathrm{HOB}$ elevation, where patients $>70 \mathrm{yr}$ had a change of $2.6 \mathrm{~mm}(99 \% \mathrm{CI}, 0.01$ to $5.1 ; \mathrm{P}=0.009)$ at $90^{\circ}$ $\mathrm{HOB}$ elevation compared with $30^{\circ}$.

Conclusion The location of the ultrasound-identified surface landmark of the CTM moves in a cephalad direction by changing the position of the HOB from supine $0^{\circ}$ to elevation at $30^{\circ}$ and $90^{\circ}$. This may be clinically important when attempting cricothyrotomy using a percutaneous (blind) technique, particularly when CTM identification and cricothyrotomy are performed at different head elevations.

\section{Résumé}

Objectif Notre objectif principal était d'évaluer la différence de position de la membrane cricothyroïdienne en tant que repère échoguidé selon qu'elle est identifiée à différentes elévations de la tête du lit avec le patient en décubitus dorsal.

Méthode Cette étude observationnelle prospective a inclus des patients se présentant à l'urgence pour des problèmes de santé ne mettant pas leur vie en danger. Les repères échoguidés de la membrane cricothyroïlienne ont été identifiés chez ces patients en positionnant la tête de lit à $0^{\circ}, 30^{\circ}$ et $90^{\circ}$. Un modèle de régression linéaire à effets mixtes a été utilisé pour évaluer les modifications du repère de la membrane cricothyroïdienne associés à la position de la tête. Nous avons utilisé un deuxième modèle linéaire à effets mixtes ajustés pour évaluer les facteurs confondants potentiels liés au patient et associés à ces changements.

Résultats Cent dix patients ont été recrutés, d'un âge médian [écart interquartile] de 39 [29-59] ans et avec un ratio femmes : hommes de $51: 49$. L'élévation de la tête de lit à $30^{\circ}$ et $90^{\circ}$ a entraîné un glissement céphalade de 2,7 mm (intervalle de confiance [IC] $99 \%, 1,7$ à 3,8; $P<0,001)$ et de 4,2 $\mathrm{mm}($ IC $99 \%, 3,2$ à 5,3; P<0,001) du marquage de la membrane cricothyroïdienne, respectivement, comparativement au repère identifié à un angle de $0^{\circ}$. L'indice de masse corporelle (IMC) était 
associé à un changement de 4,6 mm (IC $99 \%, 0,5$ à 8,7; P $=0,004)$ pour un IMC $\geq 30$, comparativement $\grave{a}<18,5$ $\mathrm{kg} \cdot \mathrm{m}^{-2}$. L'impact de l'âge du patient sur la distance dépendait de l'élévation de la tête de lit : chez les patients $>70$ ans, le changement était de 2,6 mm (IC $99 \%, 0,01$ à 5,1; $P=0$,009) à une élévation de la tête de lit de $90^{\circ}$ comparativement à un angle de $30^{\circ}$.

Conclusion L'emplacement du repère de surface identifié par échoguidage de la membrane cricothyroïlienne se déplace en direction céphalade lorsqu'on change la position de la tête de lit d'un décubitus dorsal à $0^{\circ}$ à une élévation de $30^{\circ}$ et $90^{\circ}$. Cela pourrait avoir une importance clinique lors d'une tentative de cricothyrotomie à l'aide d'une technique percutanée (en aveugle), particulièrement si l'identification de la membrane cricothyrö̈ienne et la cricothyrotomie sont réalisées à différentes élévations de la tête.

Keywords cricothyrotomy - cricothyroid membrane ultrasound · airway $\cdot$ emergency department

In critical care settings, patients in respiratory distress may require a rapidly-evolving escalation of respiratory support, culminating in endotracheal intubation and mechanical ventilation. A small subset of these patients will have anatomic, physiologic, or disease-specific characteristics that make it difficult or impossible to obtain adequate ventilation using conventional techniques (e.g., bag-andmask [including naso- and oropharyngeal airways], supraglottic airway devices, and endotracheal intubation). While evolving technology using video laryngoscopy can offer advantages compared with direct laryngoscopy and flexible bronchoscopy, a surgical airway may still be necessary (e.g., front of neck surgical access via the cricothyroid membrane [CTM]), as per modern airway management algorithms). ${ }^{1}$ As such, it is important that patients requiring airway management be routinely assessed for a potential cricothyrotomy, which is becoming standard in airway management algorithms. ${ }^{2}$

In the emergency medicine literature, the incidence of a "difficult airway" (defined as difficult mask ventilation, $\geq$ three attempts at endotracheal intubation, failed intubation, or difficult cricothyrotomy) is about $4 \%,{ }^{3}$ but cricothyrotomy is required in less than $0.5 \%$ of emergency tracheal intubations. ${ }^{4}$ Cricothyrotomy initially requires external landmarking of the CTM in preparation for incision. Studies have shown that ultrasound is superior to palpation for landmarking the location of the CTM. ${ }^{5-7}$ Identification of the landmarks is traditionally performed with the patient positioned supine, the position in which the surgical procedure is to be performed. Nevertheless, patients in respiratory distress may require an upright seated position to improve oxygenation and ventilation, and to decrease work of breathing. In this context, it is unclear whether ultrasound-guided landmarking of the CTM in the upright position (as part of airway management planning) will still be a reliable landmark when the patient is repositioned supine to secure the airway. By way of analogy, when considering an ultrasound-guided lumbar puncture procedure, the surface anatomical landmarks have been shown to change with patient position, and so it is recommended that landmarks be identified by ultrasound with the patient appropriately procedure-positioned. ${ }^{8}$

The primary objective of this study was to assess whether the position of the ultrasound-guided external landmark of the CTM changes with the patient positioned at increasing head of bed (HOB) elevation $\left(30^{\circ}\right.$ and $90^{\circ}$ head-up) compared with a standardized supine HOB position $\left(0^{\circ}\right)$. The secondary objective was to determine whether the distance between landmarks at different HOB elevations was affected by various patient factors, including age, sex, and body mass index (BMI).

\section{Methods}

This was a prospective observational study of the landmarking of the CTM using ultrasound on a convenience sample of emergency department (ED) patients. This study was approved by the University of British Columbia (UBC) Clinical Research Ethics Board (CREB \#H17-00263, 31 March 2017). Written, informed consent was obtained from all patient participants by a study physician. We adhered to the STROBE statement for reporting of observational studies.

The study was performed at Vancouver General Hospital, an academic tertiary care hospital with an annual census of 95,000 ED visits. It is affiliated with an emergency medicine residency program. Patient enrolment occurred between 10 April 2017 and 7 May 2017. Patients were approached for possible study inclusion by one of the study investigators. Inclusion criteria were age $>18 \mathrm{yr}$, able to give informed consent, able to tolerate change in position from $0^{\circ}$ to $90^{\circ}$ of $\mathrm{HOB}$ elevation, and no interference of study participation in the patient's ED care. Exclusion criteria were a Glasgow Coma Score $<15$, critical illness, respiratory distress, hemodynamic instability, prior neck surgery or altered neck anatomy, inability to lay supine, a cervical collar, or allergy to propylene glycol or ultrasound gel.

Two emergency medicine resident physicians and one anesthesia resident physician were trained by the UBC Ultrasound Fellowship Director (D.K.) to landmark the CTM using ultrasound. This training included a one-hour 
didactic lecture and the demonstration of adequate performance during five practice scans prior to enrolling patients. These resident physicians had each performed at least 200 point of care ultrasound scans prior to enrolling patients for this study and so were comfortable with ultrasound evaluation.

On enrolment, the study physician performing ultrasound-guided landmarking recorded patient age and sex. The height and weight of each patient were measured and the BMI was calculated.

To maintain a standardized head position during measurements, subjects were initially placed supine on a hospital stretcher with a pillow under the head to achieve a "sniffing position" such that at $0^{\circ}$, an imaginary horizontal line connected the mastoid process with the sternum (ideal intubating position for adults). ${ }^{9}$ A protractor was used to achieve accurate and consistent $30^{\circ}$ and $90^{\circ} \mathrm{HOB}$ elevations (Fig. 1).

The CTM was scanned with a portable ultrasound machine (SonoSite Edge, Bothell WA, USA) connected to a high-frequency linear $\mathrm{L} 25 \mathrm{x}$ transducer $(6-13 \mathrm{MHz})$, using the transverse TACA technique ("Thyroid cartilageAirline-Cricoid cartilage-Airline"). ${ }^{10}$ The transducer was placed in a transverse orientation over the thyroid cartilage and moved caudally until the "airline" was seen-a hyperechoic white line with air reverberation artifact representing the CTM. It was then moved further caudally until the cricoid cartilage was visualized as a black C-shaped structure. Finally, the transducer was moved back in a cephalad direction to again image the "airline". Once the CTM was localized, the transducer was moved in the cephalad direction until the first "airline" disappeared, which represents the superior pole of the CTM. The site of the superior pole was confirmed by imaging in the orthogonal plane in a longitudinal orientation (Fig. 2).
A $10 \mathrm{~cm} \times 12 \mathrm{~cm}$ Tegaderm (3M, Maplewood, MN, USA) transparent film was applied to each patient's neck to facilitate marking the position of the CTM in the three different HOB positions. With the patient supine and HOB elevation at $0^{\circ}$, the superior pole of the CTM was identified and marked with a 2-mm pen. The patient's HOB was then raised to $30^{\circ}$, the superior pole of the CTM was identified, and the distance of this landmark from the reference landmark at $0^{\circ}$ was measured using a measuring tape. The patient's HOB was then raised to $90^{\circ}$ and the superior pole of the CTM was again identified, and the distance from the reference landmark at $0^{\circ}$ was measured. These measurements were performed once at each position. Positive and negative differences were used when measuring the distance between landmarks. To account for the thickness of the pen marking, all measurements were completed using the caudal edge of the pen marking. All scans were recorded, and a random sample of $10 \%$ was

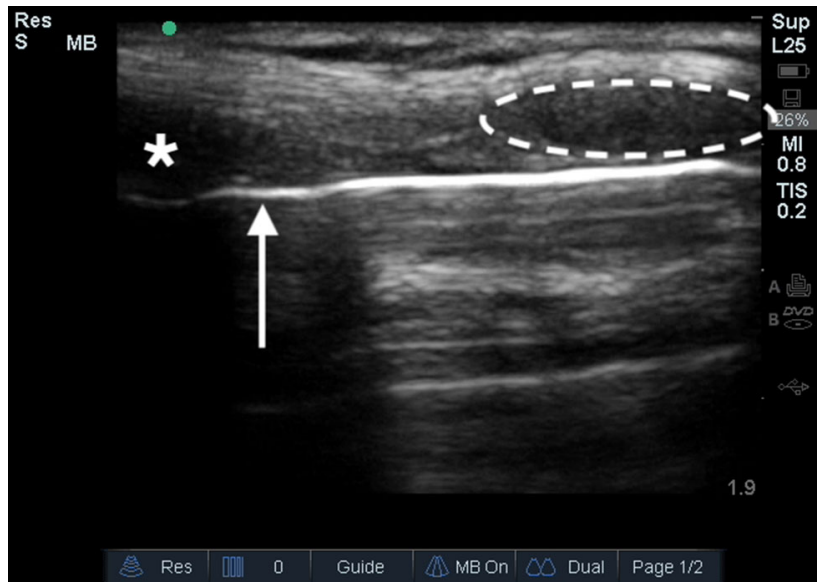

FIG. 2 Sonographic image obtained in longitudinal orientation of the thyroid cartilage (asterisk), superior pole of the cricothyroid membrane (arrow), and cricoid cartilage (oval outline).
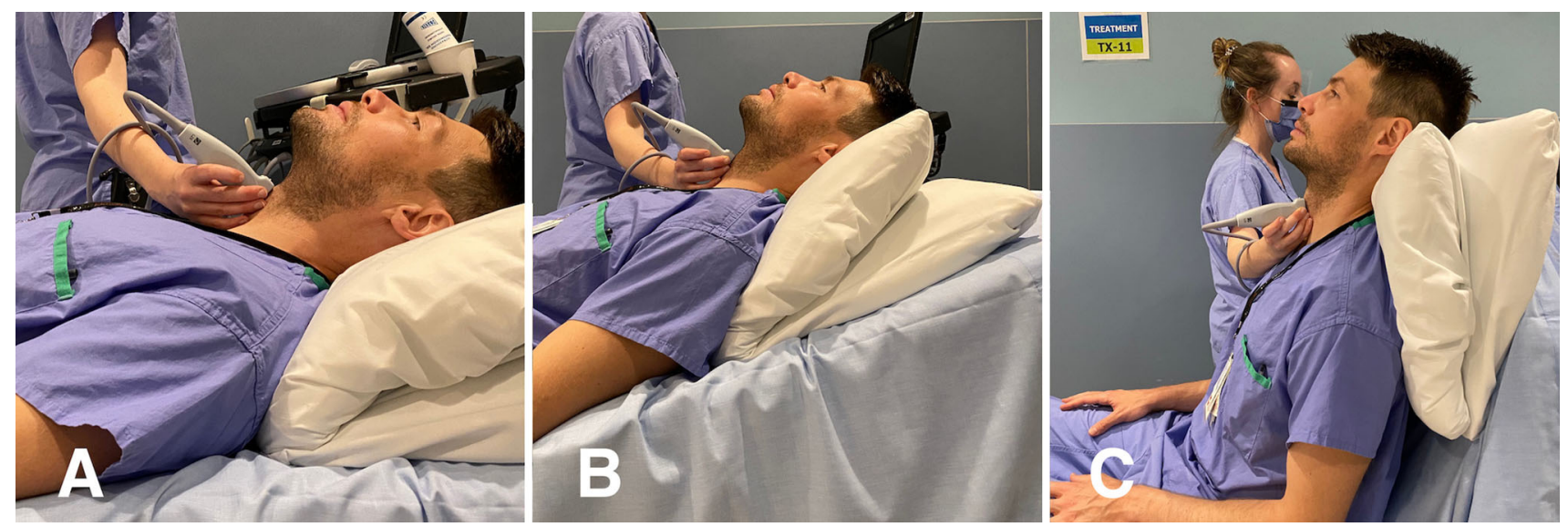

FIG. 1 Example of cricothyroid membrane (CTM) ultrasound scanning in a volunteer. Subjects were positioned supine, in the "sniffing" position, with $\mathrm{CTM}$ landmarking performed at $0^{\circ}(\mathrm{A}), 30^{\circ}(\mathrm{B})$, and $90^{\circ}(\mathrm{C})$ head of bed elevation. Used with permission. 
subsequently reviewed for accuracy by the Ultrasound Fellowship Director (D.K.).

Anonymized patient data were entered into a Microsoft Excel (Microsoft, Redmond, WA, USA) spreadsheet. All statistical analyses were performed using $\mathrm{R}$ version 3.5.1 (R Foundation for Statistical Computing, Vienna, Austria). To address our primary objective, we used a linear mixed effects regression model with the response variable being the distance (in $\mathrm{mm}$ ) between the CTM external landmarks. Absolute values of the measured distance were used in data analysis so that computations of averages would have meaningful interpretations. Head of bed elevation was treated as a fixed effect and each patient had a random intercept. To address our secondary objective, we fit another model that included possible confounding factors and interactions with each factor and HOB elevation. These factors were patient age, sex, and BMI. To address multiple inferences involving HOB elevation, we consider $P<0.01$ as statistically significant and report corresponding $99 \%$ confidence intervals (CI) for all regression coefficient estimates.

To detect a medium effect size of $6 \%$ on the distances measured between CTM landmarks $(80 \%$ power, alpha 0.05), we calculated that we needed to enrol a sample size of 53 patients. As there was no previous research to help guide us, the $6 \%$ effect size was based on Cohen ${ }^{11}$ who suggested that "small", "medium" and "large" effects occur when $1 \%, 6 \%$, and $14 \%$ of the variability in data respectively can be explained by the factor of interest (HOB elevation). The observed variance in distance to landmark in this study was $17.5 \mathrm{~mm}^{2}$, which implies a "medium" effect size of approximately $1.05 \mathrm{~mm}^{2}$, or equivalently $1.02 \mathrm{~mm}$ (variance $=17.5 \mathrm{~mm}^{2}$; medium effect $=6 \%$ of variance $=0.06 \times 17.5=1.05 \mathrm{~mm}^{2} ; \sqrt{ } 1.05$ $\mathrm{mm}^{2}=1.02 \mathrm{~mm}$ ).

\section{Results}

$>$ A total of 110 patients were enrolled. The median [interquartile range] age was 39 [29-59] yr, and 51\% were female (Table 1). Four patients had incomplete demographic data and were excluded from the secondary analysis.

Using ultrasound for CTM landmarking, HOB elevation at $30^{\circ}$ and $90^{\circ}$ resulted in a cephalad change of $2.7 \mathrm{~mm}$ (99\% CI, 1.7 to $3.8 ; P<0.001)$ and $4.2 \mathrm{~mm}(99 \% \mathrm{CI}, 3.2$ to 5.3; $P<0.001)$, respectively, compared with the landmark at $0^{\circ}$ (Table 2 and Fig. 3).

Body mass index was associated with a change of 4.6 mm (99\% CI, 0.5 to $8.7 ; P=0.004$ ) for $\mathrm{BMI} \geq 30$ compared with $<18.5 \mathrm{~kg} \cdot \mathrm{m}^{-2}$ (Table 3). The impact of patient age on distance depended on HOB elevation, where
TABLE 1 Patient demographics $(n=110)$

\begin{tabular}{ll}
\hline Patient characteristic & Count $(\%)$ or median [IQR] \\
\hline Age $(\mathrm{yr})$ & $39[29-59]$ \\
$\leq 30$ & $34(30.9)$ \\
$31-50$ & $38(34.5)$ \\
$51-70$ & $25(22.7)$ \\
$>70$ & $13(11.8)$ \\
Sex* & \\
Male & $53(48.2)$ \\
Female & $55(50.0)$ \\
Height $(\mathrm{m})^{* *}$ & $1.7[1.6-1.8]$ \\
Weight $(\mathrm{kg}) * *$ & $70.1[58.3-88.0]$ \\
BMI $\left(\mathrm{kg} \cdot \mathrm{m}^{-2}\right)^{* *}$ & $24.3[21-29]$ \\
$<18.5$ & $8(7.3)$ \\
$18.5-24.9$ & $50(45.5)$ \\
$25-29.9$ & $30(27.3)$ \\
$\geq 30$ & $20(18.2)$ \\
\hline
\end{tabular}

* Excludes $n=2$ patients with missing sex; **Excludes $n=2$ patients with missing height and weight. $\mathrm{BMI}=$ body mass index; IQR = interquartile range.

TABLE 2 Unadjusted linear mixed effects model with a random intercept for patient and fixed effects for head of bed angle $(n=110)$.

$\begin{array}{lll}\begin{array}{l}\text { Coefficient } \\ (\mathrm{mm})\end{array} & \text { SE } 99 \% \text { CI } & P \text { value } \\ \end{array}$

\begin{tabular}{llll}
\hline HOB angle $30^{\circ} v s$ supine & 2.7 & 0.4 & 1.7 to $3.8<0.001$ \\
HOB angle $90^{\circ} v s$ supine & 4.2 & 0.4 & 3.2 to $5.3<0.001$ \\
\hline
\end{tabular}

$\mathrm{CI}=$ confidence interval; $\mathrm{HOB}=$ head of bed; $\mathrm{SE}=$ standard error.

patients $>70 \mathrm{yr}$ had a change of $2.6 \mathrm{~mm}$ [99\% CI, 0.01 to 5.1; $P=0.009]$ at $90^{\circ} \mathrm{HOB}$ elevation compared with $30^{\circ}$.

\section{Discussion}

This study shows that the location of an ultrasound-guided surface landmark of the CTM varies with patient position. That is, with increasing $\mathrm{HOB}$ elevation $\left(30^{\circ}\right.$ and $\left.90^{\circ}\right)$, the CTM landmark moves cephalad compared with its location with the patient in the neutral $\left(0^{\circ}\right)$ position. We also found that age $>70 \mathrm{yr}$ combined with $90^{\circ} \mathrm{HOB}$ elevation and $\mathrm{BMI} \geq 30$ were associated with greater changes in CTM distance from the baseline (neutral) position. These results are consistent with previous studies indicating that the surface landmark of the CTM changes with head and neck position. ${ }^{12}$ For example, it has been shown that an extended neck position can increase the height of the CTM by $30 \%$ compared with a neutral position. ${ }^{12}$ 


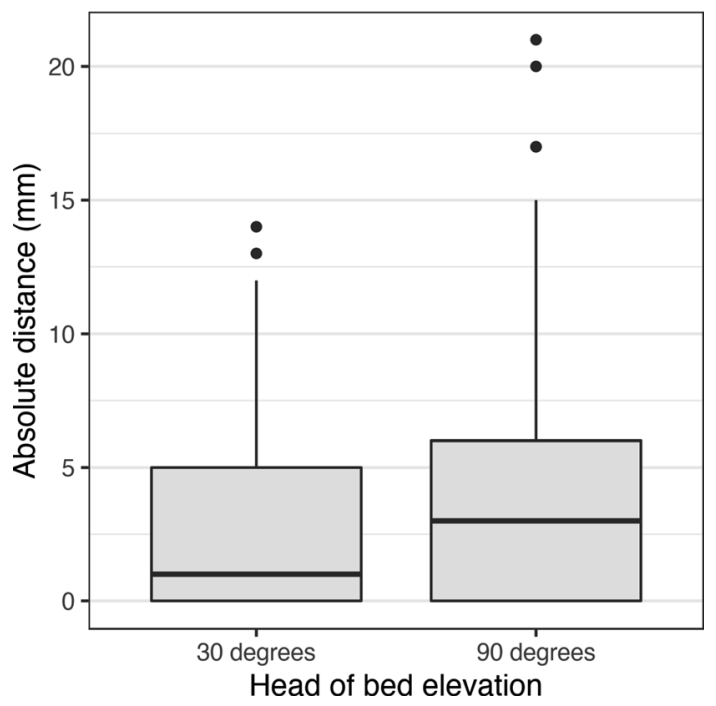

FIG. 3 Boxplot of the change in position of the cricothyroid membrane landmark with the head of bed elevation at $30^{\circ}$ and $90^{\circ}$. The first and third quartiles are represented by the horizontal boundaries of the box, and the median is the middle horizontal line running through the box. The vertical lines extend to the largest value no further than 1.5 times the interquartile range from the boundary of the box. Data beyond this boundary are represented by individual points to flag potential outlying observations.

Although the CTM landmarks change with head elevation, it is unclear if these would relate to difficulties with cricothyrotomy (i.e., inappropriate location of incision) if ultrasound-guided landmarks were obtained in the upright position prior to repositioning in the supine neutral position for cricothyrotomy. We postulate that a change in surface landmark of $\geq 5 \mathrm{~mm}$ could be clinically relevant for patients undergoing percutaneous cricothyrotomy via the Seldinger technique, where surface landmarks are used to guide the initial needle insertion. This is based on the sizing of most cannula used as part of a Seldinger technique cricothyrotomy kit having internal diameters $>4 \mathrm{~mm} \cdot{ }^{13}$ As increasing age and BMI were associated with larger position-related changes in CTM landmarkings, we would emphasize that landmarking in these patients be done in the supine neutral position whenever this is feasible. As opposed to percutaneous cricothyrotomy, open cricothyrotomy relies on tactile and visual identification of the CTM through the skin incision that guides subsequent CTM incision. Previous studies indicated a neck incision ranging from 40 to $80 \mathrm{~mm}$ in length is needed to reliably access the CTM. ${ }^{14,15}$ Based on expert opinion and the available literature, the Difficult Airway Society recommends an $80-100 \mathrm{~mm}$ vertical skin incision in patients with impalpable CTMs. ${ }^{2}$ Using these extremes, a 40-100 mm skin incision for open cricothyrotomy would likely encompass any changes in the CTM landmarks associated with head elevation.
TABLE 3 An adjusted linear mixed effects model with a random intercept for patient and fixed effects for bed angle, age, sex, BMI, and interactions between HOB angle and all other factors.

\begin{tabular}{|c|c|c|c|c|}
\hline & $\begin{array}{l}\text { Coefficient } \\
(\mathbf{m m})\end{array}$ & SE & $\begin{array}{l}99 \% \\
\text { CI }\end{array}$ & $\begin{array}{l}P \\
\text { value }\end{array}$ \\
\hline Intercept & 0.3 & 1.4 & $\begin{array}{c}-3.3 \text { to } \\
4.0\end{array}$ & 0.95 \\
\hline $\mathrm{HOB}$ angle $90^{\circ}$ vs $30^{\circ}$ & -0.2 & 1.1 & $\begin{array}{c}-3.2 \text { to } \\
2.7\end{array}$ & 0.32 \\
\hline \multicolumn{5}{|l|}{ Age } \\
\hline $31-50 v s \leq 30$ & 1.2 & 0.9 & $\begin{array}{c}-1.1 \text { to } \\
3.6\end{array}$ & 0.46 \\
\hline $51-70$ vs $\leq 30$ & 1.3 & 1.0 & $\begin{array}{c}-1.3 \text { to } \\
3.9\end{array}$ & 0.68 \\
\hline$>70 v s \leq 30$ & 2.9 & 1.2 & $\begin{array}{c}-0.2 \text { to } \\
6.0\end{array}$ & 0.03 \\
\hline Male vs female & -1.1 & 0.7 & $\begin{array}{c}-3.0 \text { to } \\
0.9\end{array}$ & 0.26 \\
\hline \multicolumn{5}{|l|}{ BMI } \\
\hline $18.5-24.9$ vs $<18.5$ & 1.2 & 1.4 & $\begin{array}{c}-2.4 \text { to } \\
4.9\end{array}$ & 0.47 \\
\hline $25-29.9 v s<18.5$ & 1.4 & 1.5 & $\begin{array}{c}-2.6 \text { to } \\
5.4\end{array}$ & 0.37 \\
\hline$\geq 30 v s<18.5$ & 4.6 & 1.6 & $\begin{array}{c}0.5 \text { to } \\
8.7\end{array}$ & 0.004 \\
\hline \multicolumn{5}{|l|}{ HOB angle $x$ age } \\
\hline $\begin{array}{l}\text { HOB angle } 90^{\circ} \text { vs } 30^{\circ} \times 31-50 \\
v s \leq 30\end{array}$ & 0.5 & 0.7 & $\begin{array}{c}-1.4 \text { to } \\
2.4\end{array}$ & 0.73 \\
\hline $\begin{array}{l}\text { HOB angle } 90^{\circ} \text { vs } 30^{\circ} \times 51-70 \\
\text { vs } \leq 30\end{array}$ & 1.9 & 0.8 & $\begin{array}{c}-0.2 \text { to } \\
4.0\end{array}$ & 0.08 \\
\hline $\begin{array}{l}\mathrm{HOB} \text { angle } 90^{\circ} v s 30^{\circ} \mathrm{x}>70 v \mathrm{~s} \\
\leq 30\end{array}$ & 2.6 & 1.0 & $\begin{array}{c}0.01 \text { to } \\
5.1\end{array}$ & 0.009 \\
\hline $\begin{array}{l}\text { HOB angle } 90^{\circ} v s 30^{\circ} \times \text { male } v s \\
\text { female }\end{array}$ & -0.1 & 0.6 & $\begin{array}{l}-1.7 \text { to } \\
1.5\end{array}$ & 0.98 \\
\hline \multicolumn{5}{|l|}{ HOB angle $x$ BMI } \\
\hline $\begin{array}{l}\text { HOB angle } 90^{\circ} v s 30^{\circ} \times 18.5- \\
24.9 v s<18.5\end{array}$ & 0.6 & 1.1 & $\begin{array}{c}-2.4 \text { to } \\
3.6\end{array}$ & 0.72 \\
\hline $\begin{array}{l}\text { HOB angle } 90^{\circ} \text { vs } 30^{\circ} \times 25- \\
29.9 \text { vs }<18.5\end{array}$ & 1.1 & 1.2 & $\begin{array}{c}-2.1 \text { to } \\
4.3\end{array}$ & 0.35 \\
\hline $\begin{array}{l}\text { HOB angle } 90^{\circ} \text { vs } 30^{\circ} \mathrm{x} \geq 30 \text { vs } \\
<18.5\end{array}$ & 2.2 & 1.3 & $\begin{array}{c}-1.2 \text { to } \\
5.5\end{array}$ & 0.22 \\
\hline
\end{tabular}

This model includes $n=106$ patients (two patients with missing BMI and two with missing sex are excluded)

$\mathrm{BMI}=$ body mass index $\mathrm{CI}=$ confidence interval; $\mathrm{HOB}=$ head of bed; $\mathrm{SE}=$ standard error.

We acknowledge the following limitations of our study. The exclusion criteria eliminated subjects with prior history of neck surgery, altered neck anatomy, immobilization in a cervical spine collar, or critical illness. Moreover, we did not assess the relationship of features such as thyromental distance, neck circumference or length on position-related changes in CTM landmarking. 
As such, the generalizability of our findings to a broader range of patients can be questioned, and there may be unrecognized anatomical characteristics that mitigate or exaggerate position-related changes in the CTM. Measurements were performed by non-blinded investigators, and so we cannot rule out this potential source of bias. Additionally, only one study investigator performed the ultrasound measurements on each subject, and each measurement was done only once, so we were unable to assess inter- or intra-rater reliability. Participants were required to maintain their head and neck in the "sniffing position" throughout the changes in HOB elevation and ultrasound-guided landmarking, and we cannot rule out subtle changes in posture over time. The use of a Tegaderm may be another potential confounder, as it may artificially hold the tissue in place with changes in HOB elevation.

In conclusion, the location of the surface landmark of the CTM moves in a cephalad position when changing the position of the HOB from supine $0^{\circ}$ to elevation at $30^{\circ}$ and $90^{\circ}$. This may be clinically important when attempting cricothyrotomy using a percutaneous (blind) technique, when CTM landmarking and cricothyrotomy are performed at different head elevations.

Acknowledgements The authors would like to thank Dr. Jonathan Lee, Dr. Hao Chen, and Dr. Margaret Zhang for assistance with patient enrolment and data collection.

Author contributions Daniel J. Kim conceived and designed the study, with input during the process from Shannon Erdelyi. Daniel $J$. Kim implemented the study and collected data. Shannon Erdelyi maintained and analyzed the data. Lauren Arthurs and Daniel J. Kim drafted the manuscript. All authors contributed substantially to its revision. Daniel J. Kim takes responsibility for the paper as a whole.

Disclosures LA and SE do not report any conflicts of interest. DJK is on the medical advisory board of Clarius Mobile Health.

Funding statement None.

Editorial responsibility This submission was handled by Dr. Steven Backman, Associate Editor, Canadian Journal of Anesthesia.

\section{References}

1. Apfelbaum JL, Hagberg CA, Caplan RA, et al. Practice guidelines for management of the difficult airway: an updated report by the American Society of Anesthesiologists Task Force on Management of the Difficult Airway. Anesthesiology 2013; 118: 251-70.
2. Frerk C, Mitchell VS, McNarry AF, et al. Difficult Airway Society 2015 guidelines for management of unanticipated difficult intubation in adults. Br J Anaesth 2015; 115: 827-48.

3. Wong E, Ng YY. The difficult airway in the emergency department. Int J Emerg Med 2008; 1: 107-11.

4. Brown CA 3rd, Bair AE, Pallin DJ, Walls RM, NEAR III Investigators. Techniques, success, and adverse events of emergency department adult intubations. Ann Emerg Med 2015; 65: 363-70.e1.

5. Elliott DS, Baker PA, Scott MR, Birch CW, Thompson JM. Accuracy of surface landmark identification for cannula cricothyroidotomy. Anaesthesia 2010; 65: 889-94.

6. Bair AE, Chima R. The inaccuracy of using landmark techniques for cricothyroid membrane identification: a comparison of three techniques. Acad Emerg Med 2015; 22: 908-14.

7. Siddiqui $N, Y u E$, Boulis $S, Y o u-T e n K E$. Ultrasound is superior to palpation in identifying the cricothyroid membrane in subjects with poorly defined neck landmarks: a randomized clinical trial. Anesthesiology 2018; 129: 1132-9.

8. Sandoval M, Shestak W, Stürmann K, Hsu C. Optimal patient position for lumbar puncture, measured by ultrasonography. Emerg Radiol 2004; 10: 179-81.

9. Adnet F, Baillard C, Borron SW, et al. Randomized study comparing the "sniffing position" with simple head extension for laryngoscopic view in elective surgery patients. Anesthesiology 2001; 95: 83641.

10. Kristensen MS, Teoh WH, Rudolph SS. Ultrasonographic identification of the cricothyroid membrane: Best evidence, techniques, and clinical impact. Br J Anaesth 2016; 117(Suppl 1): i39-48.

11. Cohen J. Statistical Power Analysis for the Behavioral Sciences. 2nd ed. Hillsdale, NJ: Lawrence Earlbaum Associates; 1988.

12. Dixit A, Ramaswamy KK, Perera S, Sukumar V, Frerk C. Impact of change in head and neck position on ultrasound localisation of the cricothyroid membrane: an observational study. Anaesthesia 2019; 74: 29-32.

13. Kristensen MS, Teoh WH, Baker PA. Percutaneous emergency airway access; prevention, preparation, technique and training. $\mathrm{Br}$ J Anaesth 2015; 114: 357-61.

14. Fennessy P, Drew T, Husarova V, Duggan M, McCaul CL. Emergency cricothyroidotomy: an observational study to estimate optimal incision position and length. Br J Anaesth 2019; 122: 263-8.

15. Duggan LV, Brindley $P G$, Law JA. Improving communication, teamwork, and action during a "cannot intubate cannot oxygenate (CICO)" emergency: employing CICO as a cognitive aid mnemonic. Can J Anesth 2018; 65: 1087-92.

Publisher's Note Springer Nature remains neutral with regard to jurisdictional claims in published maps and institutional affiliations. 